\title{
THE ESTIMATION OF INFLATION-ADJUSTED EARNINGS TO STOCK VALUE RATIO"
}

\section{Aleksandr B. MOLOTKOV}

independent expert, Moscow, Russian Federation abm91@rambler.ru https://orcid.org/0000-0003-3007-3473

\section{Article history: \\ Article No. 50/2021 \\ Received 25 January 2021 \\ Received in revised form \\ 12 February 2021 \\ Accepted 26 Feb 2021 \\ Available online \\ 30 March 2021}

JEL classification: C51, E31, G12, G17

Keywords: stock market, Earningsprice ratio, Risk premium, Inflation, Stock value, Gordon model

\section{Abstract}

Subject. The study discusses the dependence of estimates of the fundamental stock value (based on the earnings-price ratio) on the expected inflation.

Objectives. I determine the type and parameters of such dependence.

Methods. The research is based on methods for estimating the stock value and regression analysis to define the parameters of the suggested model.

Results. For the US stock market (S\&P 500 index), it is shown that earningsprice ratio for the earnings averaged over 10 years has a significant positive correlation with the indicator chosen to characterize the expected inflation. It is substantiated that the main reason is the impact of the expected inflation on the real determinants of the fundamental value, primarily on the risk premium. Conditions are formulated under which Gordon's formula can be used to determine the type of relationship between the fundamental stock value and its determinants for a time series of observations with a changing real discount rate.

Conclusions. The model is suggested for estimating the fundamental stock value based on the linear relationship between the earnings-price ratio and inflation., and its parameters are determined. The adequacy of the model is confirmed empirically for the US stock market. The findings can complement investor's decision-making methods in the stock market.

(c) Publishing house FINANCE and CREDIT, 2021

Please cite this article as: Molotkov A.B. The Estimation of Inflation-Adjusted Earnings to Stock Value Ratio. Digest Finance, 2021, vol. 26, iss. 1, pp. 53-66.

https://doi.org/10.24891/df.26.1.53

\section{Introduction}

The estimation of the fundamental value of assets is highly important for investors and has a long history of research. The broad consensus is summarized in equating the fundamental value of an asset to the sum of discounted cash flows received by the investor. For stocks, the Dividend Discount Model (DDM) is used most often. However, the model's parameters (discount rate and growth rates) are difficult to set up adequately enough for a long period. Therefore, based on this model, indicators were proposed, such as price-earnings $(\mathrm{P} / \mathrm{E})$ ratio, earnings-price $(\mathrm{E} / \mathrm{P})$ ratio, as well as dividend yield and

\footnotetext{
"The English text is provided by the author.
} 
earnings yield, which, under some assumptions, allow to estimate fundamental parameters based on the observed variables.

These indicators are used to form hypotheses about expected returns and to reconcile the indicators and benchmarks of the fundamental stock value [1-6].

J.Y. Campbell and R.J. Shiller [5], as for dataset extending the S\&P 500 Index from 1872, showed convincingly that the deviation of estimates of $(P / E)_{t}$ at the $t$-point from standard value indicates, first of all, the deviation of stock prices from their fundamental value. The historical mean is used as the standard value. That is, the model that allows to estimate the fundamental stock value for a selected long interval can be written as follows:

$(V / E)_{t}=(P / E)_{m n}=$ const

$V$ is an estimate of fundamental stock value, $(V / E)_{t}$ is the value $V / E$ ratio at the point $t,(P / E)_{m n}$ is the mean ratio over a long period.

In this study, it is believed that the possibility of using the mean as estimation ratios for fundamental parameters is based on assumptions, some of which need to be further discussed. In particular, the invariability of expected real indicators (discount rate and growth rates) under changing market conditions, including changes in the inflation rate.

In this study, I attempt to design a model that allows to correct the estimate of the earnings-price ratio for the fundamental stock value $(E / V)_{t}$, depending on changes in the expected rate of inflation.

The proposed model is as follows:

$(E / V)_{t}=(E / P)_{m n}+b\left(I_{t}-I_{m n}\right)$;

$b$ is a coefficient close to $1, I_{t}$ is an indicator of the long-term expected inflation at the point $t, I_{m n}$ is the mean of $I_{t}$ within the selected long-term interval.

The $E / P$ ratio is used, since exactly this ratio can be represented as a linear relationship with inflation, under certain assumptions, and gives a high level of determination for the regression model.

The relationship between ratios for the estimation and inflation was considered earlier by the following major aspects. First, there is a money illusion and misjudgment of the stock market by investors [7-9]. Second, there is a direct relationship between $E / P$ and the nominal yield of government bonds, according to the Fed model [10-14]. Third, there is the relationship between real expected parameters, such as the discount rate and dividend (earnings) growth rates, and inflation [14-17].

This paper concerns the third direction. 
It is important for the regression model to use observed values as explanatory variables rather than their estimates. Therefore, the expected inflation rate is calculated based on historical data. Following J.Y. Campbell and R.J. Shiller [5], the 10-year average earnings are used in the earnings-price ratio instead of current earnings. In the proposed work, it is shown that the E/P ratio, based on the earnings averaged over 10 years, has a significant and positive correlation with the inflation rate averaged over the last five years. According to quarterly data for different time intervals after World War II, linear regression gives a high level of determination of more than $70 \%$, and regression parameters are significant (within 1881-2019, the coefficient of determination is 26\%).

The experiments concerned the U.S. market (S\&P 500 Index) ${ }^{1}$.

\section{The Basis for the Model}

The negative dependence of the $\mathrm{P} / \mathrm{E}$ ratio (inverse to the ratio considered herein) on the expected inflation was indicated by F. Modigliani and R.A. Cohn [7]. The money illusion and the stock market incorrectly evaluated by investors were found to be the main reason within the 1960-1970s. This hypothesis was supported by some authors [8,9] and widely accepted. This rationale, apparently, can apply to certain time intervals to explain local irrational actions of investors, but as a general statement leads us to a negation of either empirical data or the Dividend Discount Model (DDM). DDM does not provide for a combination of nominal and real variables.

That is, the discrepancy between the observed values and the model's estimates may arise from properties of variables used in the model. This possibility is also mentioned by F. Modigliani and R.A. Cohn [7]. It is an effect of inflation on the required real rate of return.

According to the Fed model, there is a direct relationship between E/P (or earnings yield) and the nominal yield of government bonds, which includes the expected inflation. When the earnings yield is lower than the yield on government bonds, the stock market is overestimated and vice versa. Thus, stock returns may be efficiently predicted. The model is very popular, but its adequacy and the practical application are viewed differently in the scientific literature. The main complaints about the model are that the earnings yield, that has a real expression, is equated to the nominal yield, and the very possibility of using the model to predict stock returns is not confirmed [10-13]. It is pointed out that the main component responsible for the correlation of stock and bond returns is the expected inflation [14].

Moreover, it should be noted that the ability to predict returns based on E/P rests on the assumption that the value of this indicator is constant for the fundamental stock value. Otherwise, there should an additional assumption about the equal rate of the expected inflation at the beginning and the end of the holding period.

${ }^{1}$ URL: http://www.econ.yale.edu/ shiller/data.htm 
It is well-known that the $\mathrm{E} / \mathrm{P}, \mathrm{P} / \mathrm{E}$ ratios for the fundamental stock value can be expressed in terms of nominal and real variables. In this case, values do not change. That is, the dependence of real variables of the DDM (real expected returns and (or) real earnings growth rates) on inflation is the only explanation of the dependence of these ratios on inflation. Thus, in particular, S.A. Sharpe [16] argues that the negative relationship between $\mathrm{P} / \mathrm{E}$ and expected inflation may result from two effects, i.e. a lower expected growth in real earnings and a higher real required returns when inflation rises.

As many researchers note, the negative relationship between inflation and real realized stock returns [18-22]. However, this does not mean that the statement may apply to real required returns, which determine the current stock prices.

I. Fisher [23, p. 222] mentions the difference between expected and realized future events $^{2}$. R.D. Arnott and P.L. Bernstein [24] emphasize a fundamental difference between expected and realized indicators of returns for the stock market and present a scenario that confirms this point of view with respect to 1926-2001.

Thus, investors' expectations will be expressed in predictable parameters, taking into account the expected risk. In the mean time, the level of risks and, consequently, risk premium depend on the expected inflation rate.

M. Friedman [25] argues that a higher inflation is associated with a greater volatility in inflation and a greater uncertainty about future inflation rates. B.G. Malkiel [26] notes that the high inflation rate is associated with a significant variability of the inflation rate and considerable relative price changes that make long-term planning risky. Other authors also confirm a positive correlation between rising inflation and greater uncertainty $[10,22$, 27]. Greater uncertainty leads to higher risk premium investors require in case of high inflation. A significant correlation between expected inflation and risk premium is demonstrated by G. Bekaert, E. Endstrom [14].

That is, current (consequently, expected) high inflation causes increased uncertainty about future parameters, which should entail an increase in risk premium, a higher discount rate of future cash flows and a decrease in the fundamental stock value.

Thus, real expected (required) rates of returns (and possibly expected growth earnings rates) depend on the expected inflation rate. For this study, the fact of uneven changes in the discount rate and growth rates with changes in the inflation rate is important. Moreover, as the expected inflation rate increases, the expected real rate of earnings growth lags behind the real discount rate due to a rise in risk premium. This fully explains a rise in the $\mathrm{E} / \mathrm{V}$ ratio with a growing inflation rate.

\footnotetext{
${ }^{2}$ Our present behavior can only be affected by the expected future, not the future as it will turn out but the future as it appears to us beforehand through the veil of the unknown.
} 
To formally substantiate a type of such relationship, we formulate additional conditions. Suppose that at each point of time, investors assess the market with constant long-term expected real parameters, such as growth rates of earnings $(g)$ and the discount rate $(k)$.

According to the Gordon Growth model:

$$
V=\frac{r E(1+g)}{(k-g)}
$$

where $k=k_{f r 0}+k_{r 0}+k(X), k_{f r 0}$ is real risk-free rate; $k_{r 0}$ is a constant part of risk premium; $k(X)$ is parameter-dependent component of risk premium; $X$ is a set of parameters, $X=\left\{x_{j}\right\}, j=1, m ; r$ is the dividend payout ratio. We also point out $k_{c o n}$ as a component of the discount rate, independent of the parameters $X, k_{c o n}=k_{f r 0}+k_{r 0}$.

Is it possible to use the initial series of observations to estimate the fundamental value for different values of $X$, focusing on the Gordon Growth formula?

Additionally, assume that:

1) within the analyzable interval, the real growth rate is a constant that does not depend on $X$;

2) dependence of risk premium on parameters is linear $k(X)=\sum a_{j} x_{j}$;

3) dividend payout ratio to earnings per share $(r)$ is constant.

There is an initial series of observations $\left\{(E / P)_{i}\right\}$ with different values of parameters at each point $X_{i}$, which corresponds to an unknown series of estimates of the earnings-price ratio for fundamental values $\left\{(E / V)_{i}\right\}$. Let there be a procedure for transforming the series $\left\{(E / P)_{i}\right\}$ into the series of data $\left\{(E / P)_{i}{ }^{*}\right\}$ with the same values. For example, $X_{0}$, with unchanged values of $k_{c o n}$ and $g$. Then we can apply the Gordon Growth formula to this series to estimate the fundamental values and

$$
(E / V)_{i}^{*}\left(X_{0}\right)=\frac{\left(k_{\text {con }}-g\right)}{r(1+g)}+\frac{\sum a_{j} X_{j 0}}{r(1+g)}=\text { const . }
$$

The ratio changes when values of the parameters become different at point $i$ from $X_{0}$ to $X_{i}$ is expressed by the formula:

$$
\Delta(E / V)_{i}^{*}\left(X_{i}, X_{0}\right)=\frac{\sum a_{j}\left(x_{j i}-x_{j 0}\right)}{r(1+g)} .
$$

Taking into account the assumption that the market is estimated with constant long-term expected values of growth rates and the discount rate at every moment of time, expression (3) can be applied to ratios $(E / V)_{i}$ corresponding to the initial series of observations $\left\{(E / P)_{i}\right\}$, from the ratios $(E / V)_{i}^{*}$ and 


$$
(E / V)_{i}=\frac{k_{c o n}-g}{r(1+g)}+\frac{\sum a_{j} x_{j i}}{r(1+g)} .
$$

That is, under the above conditions, the Gordon Growth formula determines the relationship of parameters used for the fundamental valuation of stocks at a variable discount rate.

If the set $X$ consists of one parameter - the expected inflation $(I)$, then $k(X)=k(I)=c I, c$-is a constant coefficient, and

$$
(E / V)_{i}=\frac{k_{c o n}-g}{r(1+g)}+\frac{c I_{i}}{r(1+g)}=a+b I_{i},
$$

where $a, b$ are constant coefficients.

Thus, under the above assumptions, the $\mathrm{E} / \mathrm{V}$ ratio is described by a linear dependence on expected inflation, and it is natural to apply the least squares method to the initial series of observations $\left\{(E / P)_{i}\right\}$ to estimate the coefficients $a, b$.

This article does not allow for the prediction of returns based on E/V. However, in the following section, realized returns are compared with estimates of returns based on the proposed model at known future inflation to confirm the closeness of the eestimates of stock value to fundamental values.

\section{Parameters of the E/P Model}

The study focuses on the U.S. stock market (S\&P 500 Index) within the period from 1945-2019, when the selected inflation indicator was only positive (from Q1 1945 to Q4 2019). Fig. 1 shows the dependencies of $E / P$ and $I$ on time ( $E$ stands for average real earnings over the last decade, including the current quarter, $\mathrm{P}$ is the index in real values on the last day of the quarter, I is average inflation over the last five years by CPI). The dynamics of these indicators obviously approximates. For comparison, the nominal yield on 10-year government bonds $(d 10)$ is also showed.

Linear regression $E / V=a+b I$ or $E / V=(E / P)_{m n}+b\left(I-I_{m n}\right)$ is built on quarterly data $\left\{E / P_{i}\right\}$. Values of Student's $t$-test are showed in parentheses in the selected interval $a=0.025$ (17.43), $b=0.974$ (29.73), which significantly exceed critical values at the significance level of 0.01 , thereby confirming statistical significance; coefficient of determination $R^{2}=75 \%$.

Within the selected interval, segments of 60 years were pointed put, for which similar regressions were constructed. The first one is 1945-2004, the last one is 1960-2019, with 16 periods in total. Each period begins with the first quarter of the first year and ends with the fourth quarter of the last year. The results are summarized in Table 1. 
The coefficient $a$ varies from 0.019 to 0.028 , the mean is 0.025 . The coefficient $b$ varies from 0.939 to 1.054 , the mean is 0.969 . $R^{2}$ varies from 70 to $84 \%$. The $E / P(I)$ relationship for 1960-2019 is showed in Fig. 2.

For further analysis, it is convenient to take $b=1$, then $a$ also changes (the last column in Table 1, the mean is 0.024).

Thus, as an approximate representation of the model, we take the expression:

$$
E / V=(E / P)_{m n}+\left(I-I_{m n}\right) \text {. }
$$

This version of the model is tested in the following paragraphs herein.

Fig. 3 and 4 show the time dependencies for 1960-2019: $E / P, E / V,(E / P)_{m n}$ and the approximation to $P$ through the proposed model - curve $V$, and through the mean of the $E / V$ ratio - curve $V\left(E / P_{m n}\right)$.

The proposed model is outwardly similar to the Fed model, but has a different rationale. Expected inflation is postulated as a variable parameter of risk premium rather than a component of the nominal yield on bonds. The constant parameter of the model (a) differs from the real risk-free rate in accordance with the relationship (5), although it includes it with a coefficient. In addition, that government bond yields are known to poorly correlate with E/P [10] for intervals embracing earlier periods (seen in Fig. 1 for 10-year average earnings). Finally, it should be noted that this article examines the ratio of ten-year average earnings per share to its price, while the Fed model concerns earnings yield using current values.

\section{Testing of the Model}

Testing involves S\&P 500 within 1960-2019. Insignificant fluctuations of the dividend payout ratio for the index allows to analyze returns instead of the overall one.

An apparent correlation of $E / P$ and expected inflation makes it difficult to predict stock returns based on this parameter. However, the possibility to predict the fundamental stock value at the end of the interval, which the investor is interested in, (given reasonable estimates of future inflation) allows to estimate the returns on index relative to current prices under the additional assumption that was already used in the second section. The expected long-term growth rate of real earnings does not depend on expected inflation. Then the formula for the price returns $\left(d_{t}\right.$, if $\left.b=1\right)$ is:

for an interval of $i$ years:

$$
d_{t}(i)=\frac{V_{t+1}}{P_{t}}-1
$$

Or 


$$
d_{t}(i)=\frac{E_{t+i}}{P_{t}(E / V)_{t+i}}-1=(1+g)^{i} \frac{(E / P)_{t}}{(E / V)_{t+i}}-1=(1+g)^{i} \frac{(E / P)_{t}}{\left[(E / V)_{m n}+\left(I_{t+i}-I_{m n}\right)\right]}-1 \text {. }
$$

The annual mean:

$$
d_{t}(1)=(1+g)\left\{\frac{(E / P)_{t}}{\left[(E / V)_{m n}+\left(I_{t+i}-I_{m n}\right)\right]}\right\}^{1 / i}-1
$$

The fundamental value estimate is used for the end of the holding period. $(E / V)_{m n}, I_{m n}$ are the mean values for the previous 60 years, relative to time $t$. Growth rates ( $g$ ) are estimated based on an exponential approximation of the dynamics of real earnings over the previous 60 years for each moment of forecasting returns.

For each point within 1960-2009 (2014), the model-based average annual price returns $d_{t}(1) 10$ (and 5) years ahead are compared to the mean annual realized price returns on the same projected segment $d_{r t}$. Estimates of projected returns are based on annual data, provided that future inflation is known reliably. The corresponding dependencies are showed in Fig. 5 and 6. Linear regression coefficients for the mean returns over 10 years: $a=0.037, b=0.973, R^{2}=69 \%$. For the average returns over 5 years: $a=0.059$, $b=0.747, R^{2}=47 \%$. Long-term forecasting expectedly gives a higher degree of determination.

The effectiveness of forecasting depends on the accuracy of inflation forecasting. The experiment is aimed at confirming the correctness of the model for assessing the current fundamental stock value, and does not characterize the efficiency of forecasting returns with unknown future inflation.

\section{Conclusions}

The presented model allows to estimate the fundamental stock value with reference to expected inflation and can serve as a decision-making tool for investors along with models for forecasting economic parameters.

The model has a theoretical substantiation based on the expanded use of the Dividend Discount Model with constant parameters. Conditions for such using are determined to analyze a time series of observations with a variable real discount rate.

The model parameters are determined for the U.S. stock market (S\&P 500 Index) based on the regression analysis. For quarterly data from different time segments within 1945-2019, linear regression of the earnings-price ratio from the selected inflation indicator gives a high level of determination over 70\%, and the regression parameters are significant. Empirical testing of the model given a known future inflation rate allows for a strong correlation between the predicted and realized price returns over a decade, with the coefficient of determination being 69\% (for a five-year interval, coefficient of determination is $47 \%$ ). 
Table 1

Values of regression coefficients $E / V=a+b I$

\begin{tabular}{lllll}
\hline Interval & $\boldsymbol{a}$ & $\boldsymbol{b}$ & $\boldsymbol{R}^{\mathbf{2} \%}$ & $\boldsymbol{a}(\boldsymbol{b}=\mathbf{1})$ \\
\hline $1945-2004$ & 0.028 & 0.939 & 71.8 & 0,025 \\
\hline $1946-2005$ & 0.027 & 0.945 & 72 & 0,025 \\
\hline $1947-2006$ & 0.027 & 0.952 & 72.2 & 0.025 \\
\hline $1948-2007$ & 0.026 & 0.957 & 71.8 & 0.025 \\
\hline $1949-2008$ & 0.026 & 0.955 & 71.2 & 0.025 \\
\hline $1950-2009$ & 0.027 & 0.942 & 70.4 & 0.024 \\
\hline $1951-2010$ & 0.027 & 0.940 & 70.1 & 0.024 \\
\hline $1952-2011$ & 0.027 & 0.943 & 70 & 0.024 \\
\hline $1953-2012$ & 0.026 & 0.942 & 70.5 & 0.024 \\
\hline $1955-2013$ & 0.025 & 0.954 & 73.4 & 0.024 \\
\hline $1956-2015$ & 0.024 & 0.967 & 75.3 & 0.023 \\
\hline $1957-2016$ & 0.024 & 0.973 & 75.8 & 0.023 \\
\hline $1958-2017$ & 0.023 & 0.989 & 77.1 & 0.023 \\
\hline $1959-2018$ & 0.021 & 1.017 & 80.1 & 0.022 \\
\hline Mean & 0.020 & 1.041 & 82.5 & 0.022 \\
\hline
\end{tabular}

Source: Authoring

\section{Figure 1}

The dynamics of indicators within 1945-2019

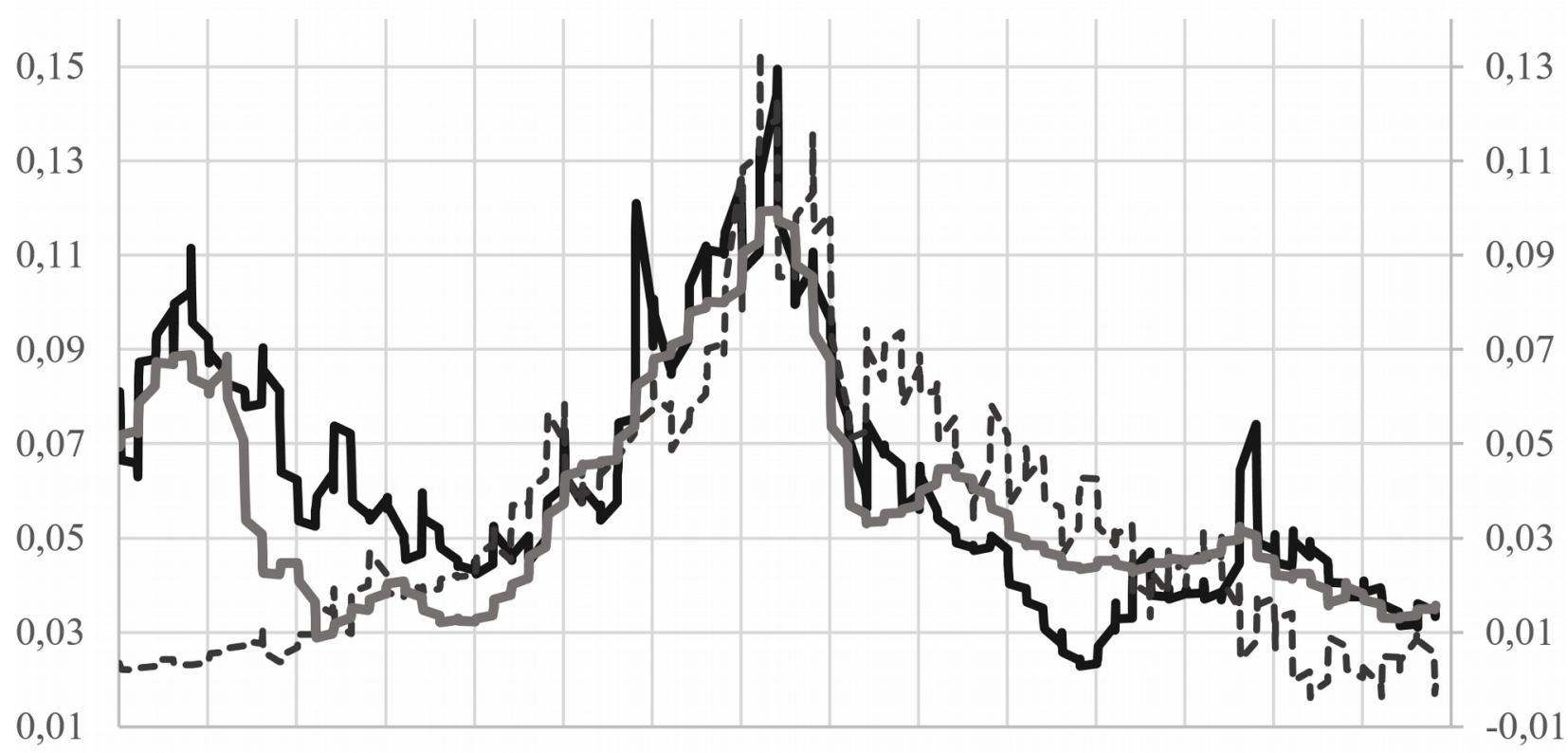

1945195019551960196519701975198019851990199520002005201020152020

Note. $E$ is the average real earnings over the last 10 years, $P$ is the index value in real terms, $I$ is the average inflation over the last five years (right axis), $d 10$ is the nominal yield on 10-year government bonds.

Source: based on data http://www.econ.yale.edu/ shiller/data.htm 
Figure 2

The relationship of $E / P$ and inflation (mean for five years) within 1960-2019

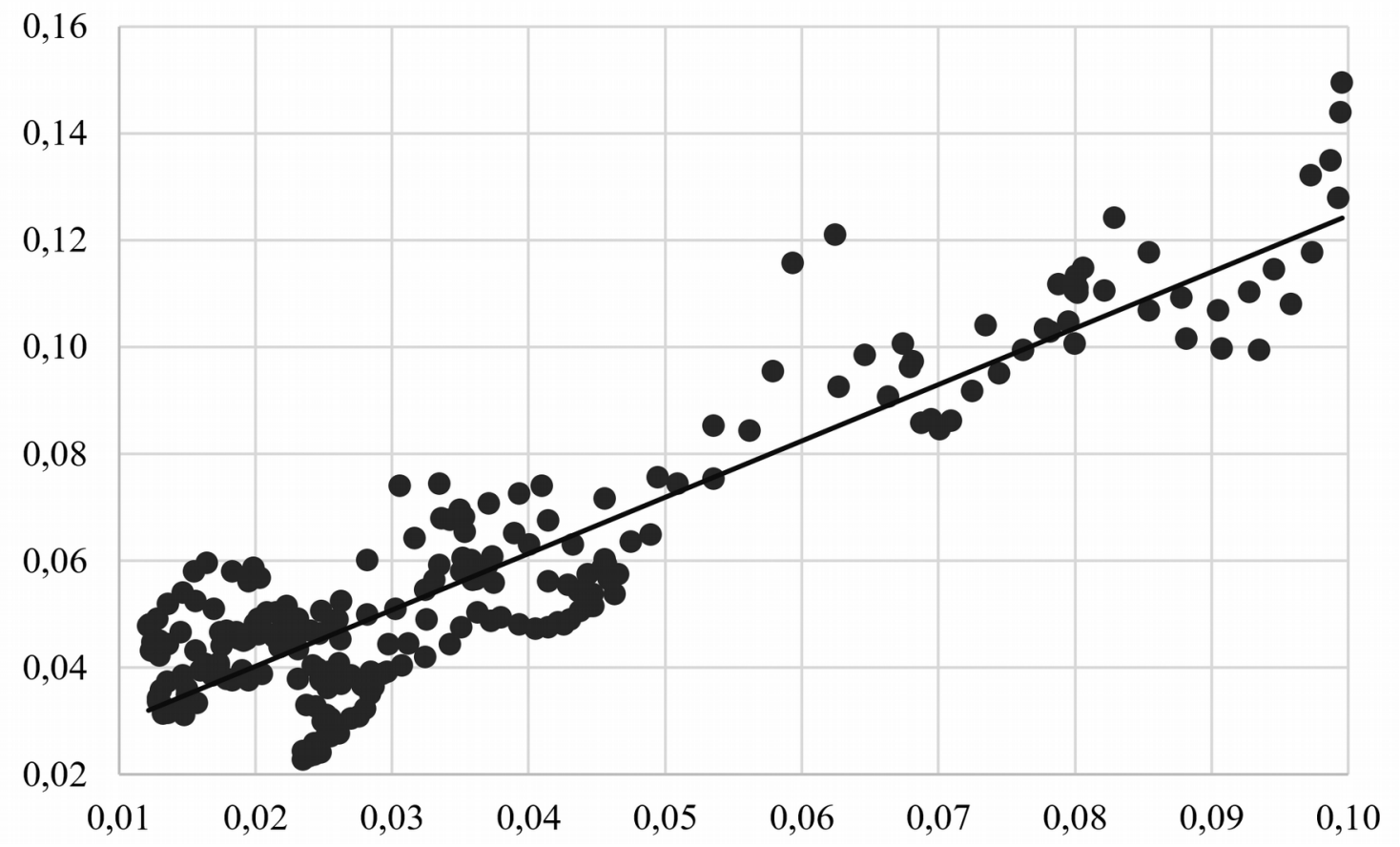

Source: Authoring

Figure 3

The dynamics of indicators within 1960-2019

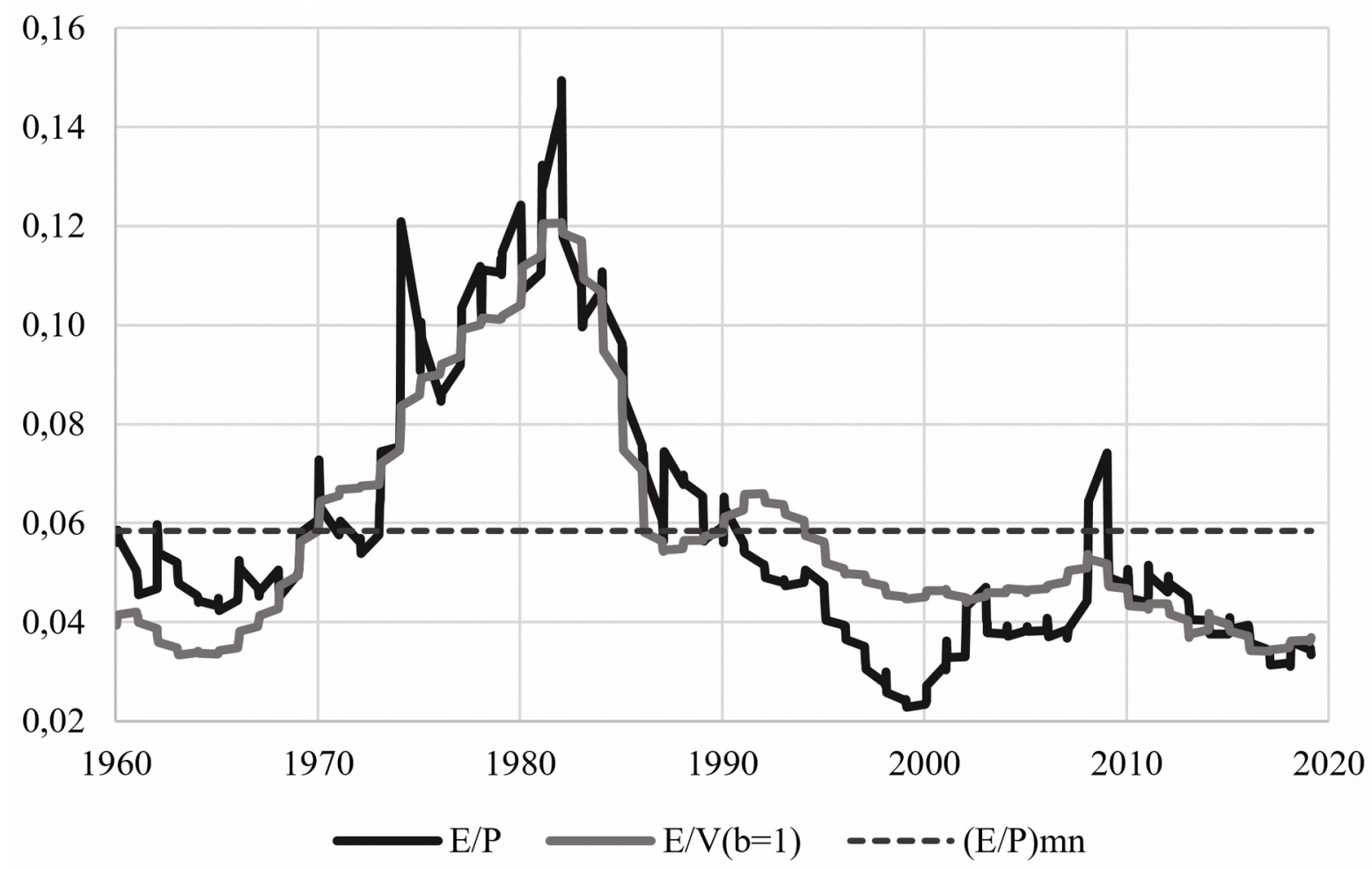

Note. $E$ is the average real earnings over the last 10 years, $P$ is the index value in real terms, $V$ is an estimate of the fundamental stock value, $(E / P)_{m n}$ is the mean of the ratio.

Source: Authoring 
Figure 4

The current prices and estimate of the fundamental value, USD

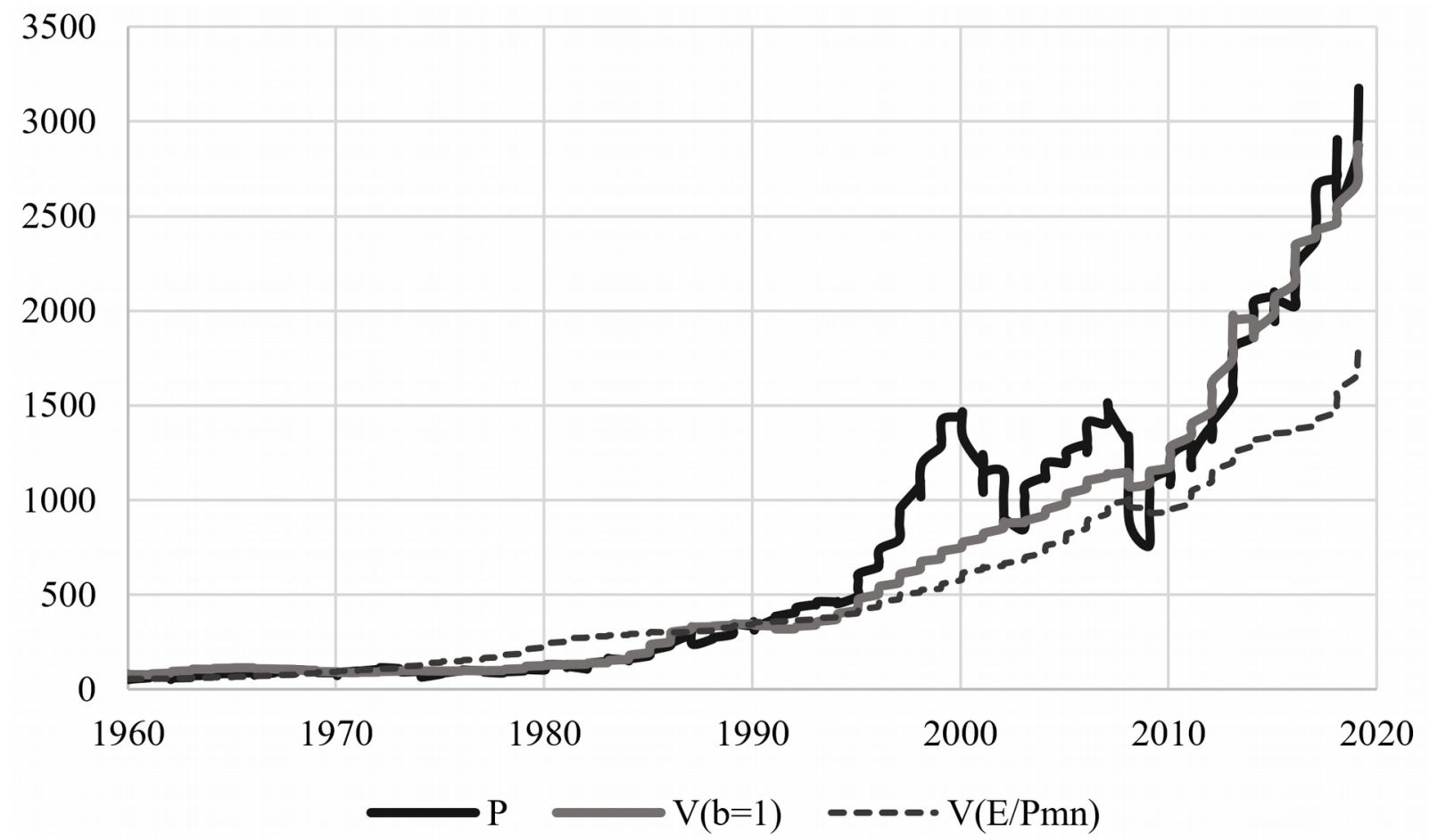

Note. $P$ is the index value in real terms, $V$ is an estimate of the fundamental stock value, $V\left(E / P_{m n}\right)$ is an estimate of the fundamental value based on the mean of the $E / V$ ratio.

Source: Authoring

Figure 5

The relationship of the mean realized and predicted price returns (a 10-year interval)

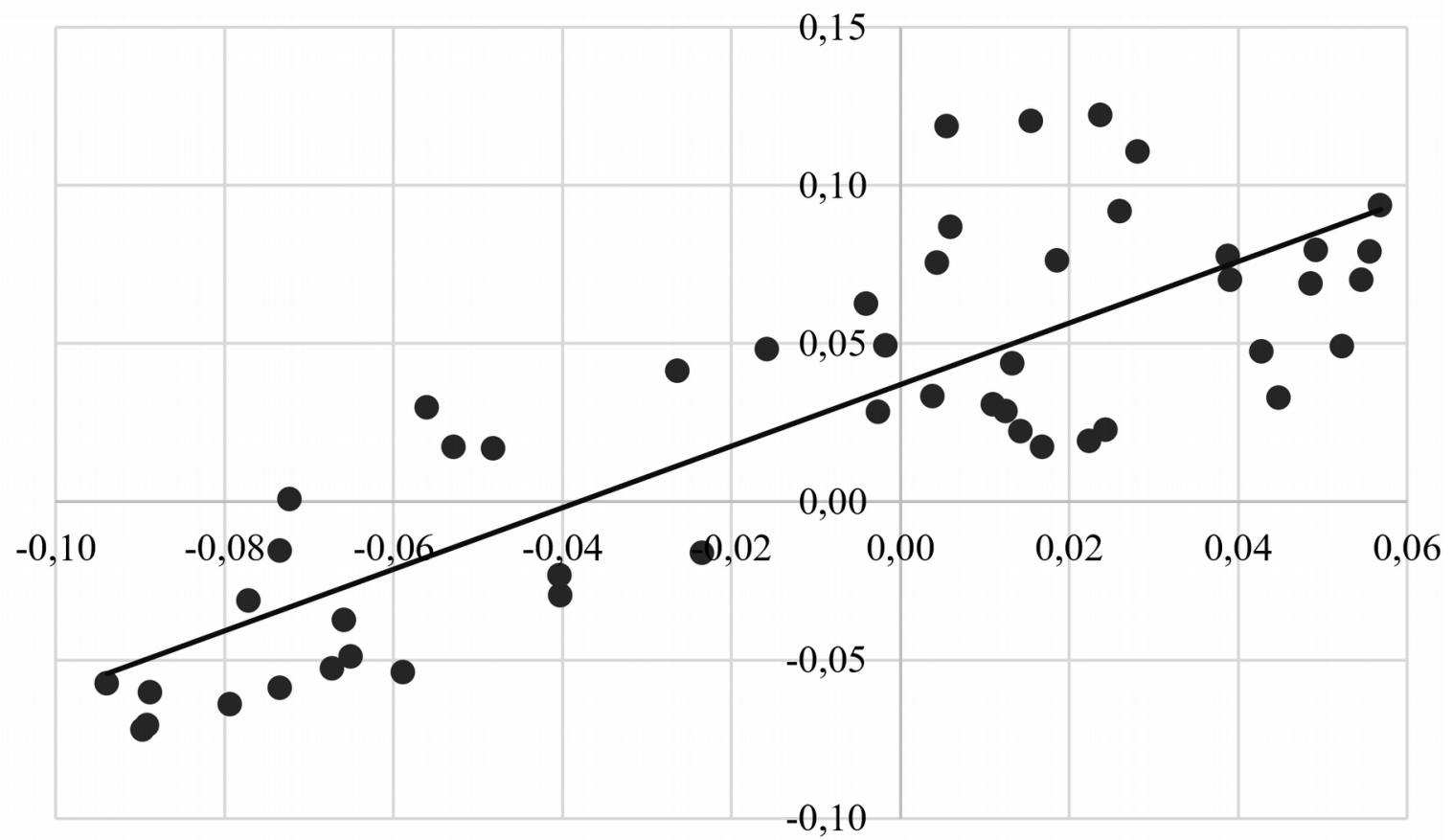

Source: Authoring 
Figure 6

The relationship of the mean realized and predicted price returns (a five-year interval)

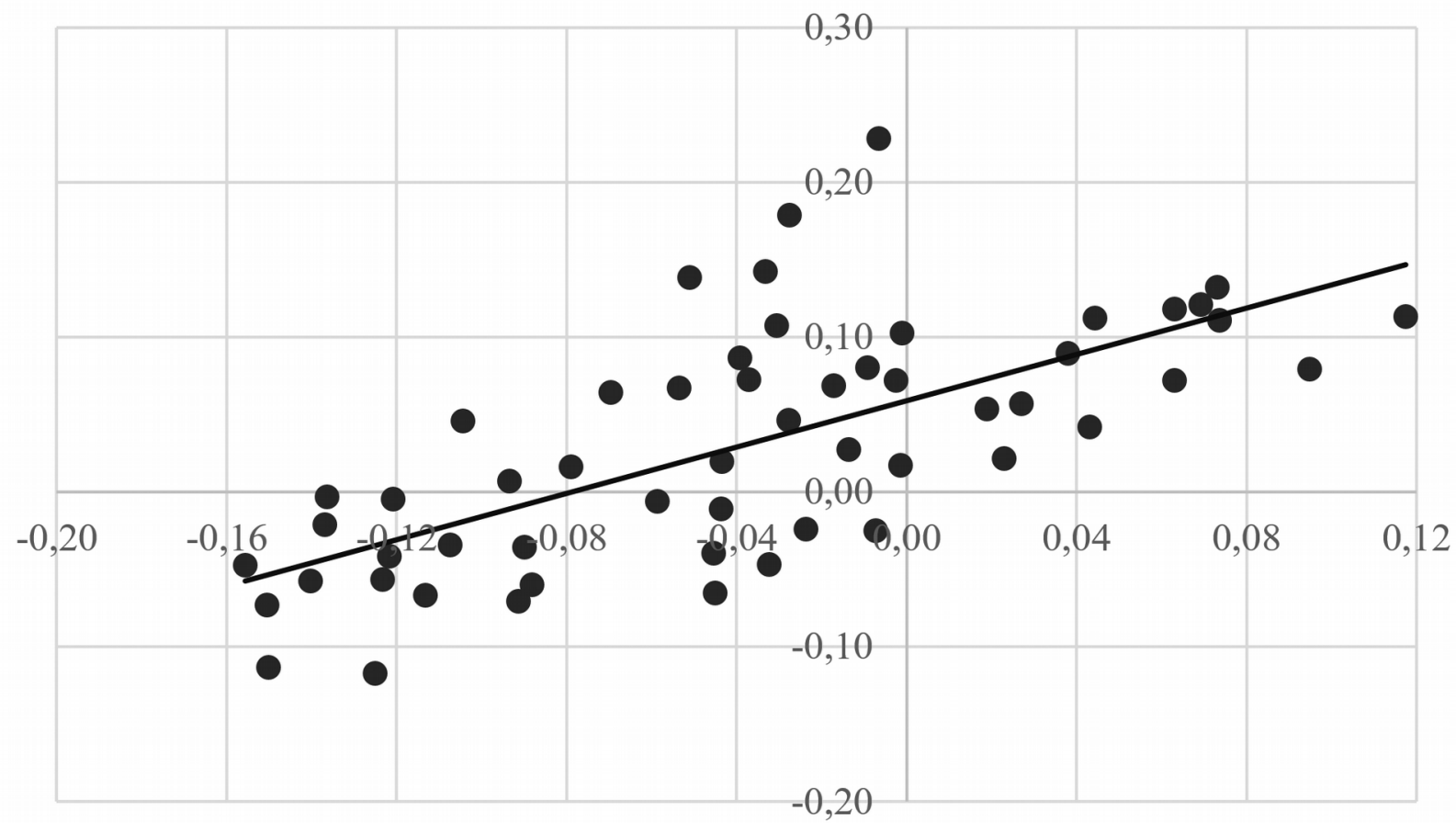

Source: Authoring

\section{References}

1. Ball R. Anomalies in Relationships between Securities' Yields and Yield Surrogates. Journal of Financial Economics, 1978, vol. 6, no. 2-3, pp. 103-126.

URL: https://doi.org/10.1016/0304-405X(78)90026-0

2. Ball R., Gerakos J., Linnainmaa J.T., Nikolaev V. Earnings, Retained Earnings, and Book-to-Market in the Cross Section of Expected Returns. Journal of Financial Economics, 2020, vol. 135, iss. 1, pp. 231-254.

URL: https://doi.org/10.1016/j.jfineco.2019.05.013

3. Campbell J.Y., Shiller R.J. Stock Prices, Earnings, and Expected Dividends.

The Journal of Finance, 1988, vol. 43, iss. 3, pp. 661-676.

URL: https://doi.org/10.1111/j.1540-6261.1988.tb04598.x

4. Campbell J.Y., Shiller R.J. The Dividend-Price Ratio and Expectations of Future Dividends and Discount Factors. The Review of Financial Studies, 1989, vol. 1, iss. 3, pp. 195-228. URL: https://doi.org/10.1093/rfs/1.3.195

5. Campbell J.Y., Shiller R.J. Valuation Ratios and the Long-Run Stock Market Outlook. Journal of Portfolio Management, 1998, vol. 24, no. 2, pp. 11-26.

URL: https://doi.org/10.3905/jpm.24.2.11 
6. Fama E. F., French K.R. Dividend Yields and Expected Stock Returns. Journal of Financial Economics, 1988, vol. 22, no. 1, pp. 3-25.

URL: https://doi.org/10.1016/0304-405X(88)90020-7

7. Modigliani F., Cohn R.A. Inflation, Rational Valuation and the Market. Financial Analysts Journal, 1979, vol. 35, iss. 2, pp. 24-44.

URL: https://doi.org/10.2469/faj.v35.n2.24

8. Ritter J.R., Warr R.S. The Decline of Inflation and the Bull Market of 1982-1999. Journal of Financial and Quantitative Analysis, 2002, vol. 37, no. 1, pp. 29-61. URL: https://doi.org/10.2307/3594994

9. Campbell J.Y., Vuolteenaho T. Inflation Illusion and Stock Prices. The American Economic Review, 2004, vol. 94, no. 2, pp. 19-23.

URL: https://doi.org/10.1257/0002828041301533

10. Asness C.S. Fight the Fed Model. Journal of Portfolio Management, 2003, vol. 30, iss. 1, pp. 11-24. URL: https://doi.org/10.3905/jpm.2003.319916

11. Malkiel B.G. Models of Stock Market Predictability. The Journal of Financial Research, 2004, vol. 27, iss. 4, pp. 449-459.

URL: https://doi.org/10.1111/j.1475-6803.2004.00102.x

12. Durre A., Giot P. An International Analysis of Earnings, Stock Prices and Bond Yields. Journal of Business Finance \& Accounting, 2007, vol. 34, iss. 3-4, pp. 613-641. URL: https://doi.org/10.1111/j.1468-5957.2007.02010.x

13. Aubert S., Giot P. An International Test of the Fed Model. Journal of Asset Management, 2007, vol. 8, iss. 2, pp. 86-100.

URL: https://doi.org/10.1057/palgrave.jam.2250063

14. Bekaert G., Engstrom E. Inflation and the Stock Market: Understanding the "Fed Model”. Journal of Monetary Economics, 2010, vol. 57, iss. 3, pp. 278-294. URL: https://doi.org/10.1016/j.jmoneco.2010.02.004

15. Peavy J.W. III, Goodman D.A. How Inflation, Risk and Corporate Profitability Affect Common Stock Returns. Financial Analysts Journal, 1985, vol. 41, iss. 5, pp. 59-65. URL: https://doi.org/10.2469/faj.v41.n5.59

16. Sharpe S.A. Reexamining Stock Valuation And Inflation: The Implications of Analysts' Earnings Forecasts. The Review of Economics and Statistics, 2002, vol. 84, iss. 4, pp. 632-648. URL: https://doi.org/10.1162/003465302760556468

17. Boucher C. Stock Prices, Inflation and Stock Returns Predictability. Revue de l'association française de finance, 2006, vol. 27, no. 2, pp. 71-101.

URL: https://doi.org/10.3917/fina.272.0071 
18. Linter J. Inflation and Security Returns. The Journal of Finance, 1975, vol. 30, no. 2, pp. 259-280. URL: https://doi.org/10.2307/2978713

19. Nelson C.R. Inflation and Rates of Return on Common Stocks. The Journal of Finance, 1976, vol. XXXI, no. 2, pp. 471-483.

URL: https://doi.org/10.1111/j.1540-6261.1976.tb01900.x

20. Fama E.F., Schwert W.O. Asset Returns and Inflation. Journal of Financial Economics, 1977, vol. 5, iss. 2, pp. 115-146.

URL: https://doi.org/10.1016/0304-405X(77)90014-9

21. Fama E.F. Stock Returns, Real Activity, Inflation, and Money. The American Economic Review, 1981, vol. 71, no. 4, pp. 545-565.

URL: https://www.jstor.org/stable/1806180

22.Hu X., Willett T.D. The Variability of Inflation and Real Stock Returns. Applied Financial Economies, 2000, vol. 10, iss. 6, pp. 655-665.

URL: https://doi.org/10.1080/096031000438006

23. Fisher I. The Theory of Interest as Determined by Impatience to Spend Income and Opportunity to Invest it. New York, The Macmillan Company, 1930, 566 p.

24. Arnott R. D., Bernstein P.L. What Risk Premium Is "Normal"? Financial Analysts Journal, 2002, vol. 58, iss. 2, pp. 64-85.

URL: https://doi.org/10.2469/faj.v58.n2.2524

25. Friedman M. Nobel Lecture: Inflation and Unemployment. The Journal of Political Economy, 1977, vol. 85, no. 3, pp. 451-472.

URL: https://www.jstor.org/stable/1830192

26. Malkiel B.G. The Capital Formation Problem in the United States. The Journal of Finance, 1979, vol. 34, no. 2, pp. 291-306.

URL: https://doi.org/10.1111/j.1540-6261.1979.tb02092.x

27. Ball L. Why Does High Inflation Raise Inflation Uncertainty? Journal of Monetary Economics, 1992, vol. 29, iss. 3, pp. 371-388.

URL: https://doi.org/10.1016/0304-3932(92)90032-W

\section{Conflict-of-interest notification}

I, the author of this article, bindingly and explicitly declare of the partial and total lack of actual or potential conflict of interest with any other third party whatsoever, which may arise as a result of the publication of this article. This statement relates to the study, data collection and interpretation, writing and preparation of the article, and the decision to submit the manuscript for publication. 